\title{
Antimicrobial Activity of Chitosan Membranes against Staphylococcus aureus of Clinical Origin
}

\author{
Ana A. Escárcega-Galaz, Jaime López-Cervantes, \\ Dalia I. Sánchez-Machado, Olga R. Brito-Zurita and \\ Olga N. Campas-Baypoli
}

Additional information is available at the end of the chapter

http://dx.doi.org/10.5772/65980

\begin{abstract}
Healthy human skin has beneficial microflora and many pathogens causing infections. Staphylococcus aureus is the most prevalent and can have multiresistance to antibiotics. Chitosan is a polysaccharide composed of glucosamine and N-acetyl-D-glucosamine, which is biodegradable and has antimicrobial activity. As part of a national scientific research project for the development and application of biomaterials, we decided to study the effect of different membranes based on chitosan against strains of S. aureus isolated from infected ulcers. The study found that seven of nine strains of $S$. aureus are sensitive to rifampin and the least eight of nine strains were multiresistant to more than ten antibiotics. Allchitosan-based membranesconfirmits antimicrobialeffectondirectcontact with an increase in its diameter. The contact area of the membranes is increased according to the concentration of chitosan. The highest average area increase was the chitosan membranes with honey and glycerin, $88.32 \%$. Chitosan membranes have shown their effectiveness against $S$. aureus strains of clinical origin. Thus, these materials can be applied for the treatment of chronic ulcers without toxic hazards and resistance caused by antibiotics.
\end{abstract}

Keywords: chitosan, antimicrobial membranes, ulcer, biomaterials, pathogens 


\section{Introduction}

Staphylococcus aureus is an infectious microorganism that can be both community- and hospitalacquired. Among the microorganisms causing nosocomial infections, it is second in prevalence $(10.6 \%)$ of infection in surgical areas, intensive care, and pediatric areas [1, 2]. Similarly, this Gram-positive pathogen is the infectious agent in a broad spectrum of diseases from skin abscesses, dermatitis, surgical wounds, bacteremia, and osteomyelitis. The antimicrobial treatment of S.aureusinfectionshas becomemorecomplicated by theincrease of abroad spectrum of antibiotics and the development of resistant strains.

Chitosan is a cationic linear polysaccharide composed of glucosamine and N-acetyl glucosamine units linked by $\beta$ (1-4) glucoside bonds [3]. This polymer is biodegradable and has antimicrobial activity against S. aureus, Escherichia coli, Salmonella typhimurium, and fungi [4]. The antimicrobial effect of chitosan is attributed to positive charges of the polymer chain. Thus, by increasing the amount of amino groups protonated, antimicrobial activity is enhanced by affecting the permeability of the bacterial cell wall. Due to its antimicrobial activity, it has been used in food preservation as antimicrobial coating of bread, fruit, vegetables, eggs, and various meat products. Because of their lack of toxicity and allergenicity, chitosan is a biomaterial with pharmaceutical and medical applications. Thus, chitosan has been used in health care products such as curing agent, dressings, skin grafts [3], hemostat, and drug carrier [5]. These biomaterials can be prepared in the form of hydrogels, membranes, and sponges.

The skin surface is characterized by a slightly acidic $\mathrm{pH}$ that favors the development of some bacteria [6]. However, in an open wound, within the first $24-48 \mathrm{~h}$ can be found Streptococcus, S. aureus, and Pseudomonas aeruginosa and then, between days 5 and 7, the bacteria found were Klebsiella and Escherichia coli [7].

Skin infections affect the epidermis, subcutaneous tissue, and muscle. Some of them require hospital admission for antimicrobial or surgical treatment. Depending on their severity, they have been associated with increased hospital stays and medical costs because traditional antibiotic treatments require long periods [8]. An alternative to antibiotics is curing materials with bioactive components. These dressings should ideally maintain a moist environment, act as antimicrobials to prevent secondary infections, remove exudate, and promote tissue regeneration $[9,10]$ One group evaluated the antimicrobial action of cotton textile impregnated with chitosan against bacteria isolated from the skin and found that chitosans of low- and highmolecular weight showed effective inhibition of $S$. aureus [11]. Another studied the effect of chitosan in antimicrobial ultrastructural organization of clinical S. aureus strains and found changes in its cell and cytoplasmic membrane. Similarly, Woo et al. [12] developed a bilayer scaffold from chitosan with $\mathrm{TiO}_{2}$ that showed high reduction in viable S. aureus. To our knowledge, there are no studies on the application of chitosan membranes against S. aureus isolated from infected ulcers of the patients hospitalized. This chapter deals with the preparation and evaluation of the effect of different membranes based on chitosan against $S$. aureus strains of clinical origin. All chitosan membranes were prepared by solvent evaporation and the antimicrobial activity was evaluated by the agar diffusion technique. 


\section{Experimentation}

\subsection{Chitosan}

Chitosan was obtained by thermo-alkaline hydrolysis of chitin, which was recovered by lactic fermentation of shrimp waste. The chitin was demineralized $\left(0.1 \mathrm{M} \mathrm{HCl}\right.$ at $25^{\circ} \mathrm{C}$ for $\left.4 \mathrm{~h}\right)$ and deproteinized $\left(4.5 \% \mathrm{NaOH}\right.$ at $65^{\circ} \mathrm{C}$ for $\left.4 \mathrm{~h}\right)$. Afterward, purified chitin was deacetylated $(40 \%$ $\mathrm{NaOH}$ at $110^{\circ} \mathrm{C}$ for $2 \mathrm{~h}$ ) to obtain chitosan, according to reported methodologies [13]. Chitosan was washed until a neutral $\mathrm{pH}$ was reached and dried at $50^{\circ} \mathrm{C}$. The purity of the chitosan was verified based on its moisture and ash content by method given in reference [14].

Degree of deacetylation of chitosan was determined by a spectrophotometric method reported by Liu et al. [15]. Briefly, two standard solutions were prepared; D-glucosamine (7.49 mM) and $\mathrm{N}$-acetylglucosamine $(0.49 \mathrm{mM})$, from these, working solutions were prepared to obtain a 12point line of different concentrations. The absorbance of the standard solutions and samples were read at $201 \mathrm{~nm}$ in a UV-Vis spectrophotometer (Genesys $10 \mathrm{UV}$, Madison, IA, USA). Finally, the degree of deacetylation was calculated with the following equation, \%DD $=(161.1$ $\times A \times V-0.0218 m) /(3.361 m-42.1 \times A \times V)$, where, $A$ is the absorbance of the sample, $V$ is the volume of dilution, and $m$ is the amount of sample in $\mathrm{mg}$.

The molecular weight of chitosan was determined as proposed by Solis et al. [16], based on the intrinsic viscosity, according to Mark-Houwink's equation $n=\mathrm{KM}_{v}{ }^{\mathrm{a}}$. Where, the reported values of $\mathrm{K}$ and a for chitosan in HAc $0.3 \mathrm{M}$ and NaAc $0.2 \mathrm{M}$ at $30^{\circ} \mathrm{C}$ are 0.074 and $0.76 \mathrm{mg}$, respectively. An Ubbelohde capillary viscometer immersed in water bath at $30 \pm 0.01^{\circ} \mathrm{C}$ was used. The falling time of solvent $\left(t_{0}\right)$ and of five polymer solutions of known concentrations $\left(t_{\mathrm{i}}\right)$ was measured.

Chitosan was identified by Fourier Transform Infrared Spectroscopy (FTIR) according to the methodology given in reference [17], with some modifications. The spectral resolution was of $4 \mathrm{~cm}^{-1}$ with 64 scans in a range of $600-4000 \mathrm{~cm}^{-1}$ using a Thermo Scientific (Nicolet5s, Madison, IA, USA) infrared spectrometer.

\subsection{Chitosan membranes}

Six chitosan based formulations using $1 \%$ acetic acid were prepared. Three pure chitosan solutions $(1,2$, and $3 \%$ ), another of $2 \%$ chitosan with glycerin (five drops per $100 \mathrm{ml}$ ) and two more solutions of $2 \%$ chitosan using honey $(95: 5, \mathrm{v} / \mathrm{v})$ with and without glycerin. For the last two solutions, honey was diluted in distilled water (80:20, v/v) and homogenized by stirring.

All chitosan membranes were prepared by solvent evaporation. For this, solutions of each formulation were poured into polypropylene plates $(10 \mathrm{ml}$ in each mold $)$ and dried at $40^{\circ} \mathrm{C}$ for $24 \mathrm{~h}$ in an oven (Felisa, Zapopan, Jalisco, Mexico). Lastly, the films were removed from the mold and stored in sterile plastic bags until use. 


\subsection{Collection and conservation of the sample}

Between June and December 2015, a descriptive and cross-sectional study was conducted in order to evaluate the effect of chitosan membranes against $S$. aureus strains isolated from skin ulcers. Patients and involved personnel confirmed their participation by giving their consent. The samples were obtained from the center of the ulcer by a medical epidemiologist. For this, a Stuart medium swab collection system (COPAN Transystem, Brescia, Italy) was used. The labeled samples were transported in a container to a certified microbiology laboratory for processing within the same hour.

\subsection{Phenotypic identification and sensitivity tests}

For microbial isolation and identification, the samples were inoculated by cross-streaking on MacConkey agar for Gram-negative bacterium and trypticase soy agar (TSA) for culture collection. Mannitol salt agar was used for Gram-positive bacterium and Biggy agar for fungi inoculated by streaking. Next, the plates were incubated at $37^{\circ} \mathrm{C}$ for bacteria and $30^{\circ} \mathrm{C}$ for fungi for $24 \mathrm{~h}$. Later, macroscopic characteristics of colony-forming units (CFU) were analyzed.

For the identification of microorganisms, a broth microdilution method was used, with an inoculation Prompt ${ }^{\mathrm{TM}}$ system precision wand. Isolated colonies were emulsified in Prompt ${ }^{\mathrm{TM}}$ innoculation bottles for an equivalent concentration of 0.08 with the McFarland standard. Next, $100 \mu \mathrm{l}$ per well were deposited in the SIEMENS microplates from a MicroScan RENOK panel which was incubated at $37^{\circ} \mathrm{C}$ for $24 \mathrm{~h}$. Specifically, type 33 plates (B1017-211) were used for Gram-positive bacteria and type 44 (B1017-305) for Gram-negative bacteria. Later, each plate was read for the identification of studied microorganisms using a LabPro Command Center software. Antibiotic sensitivity was performed simultaneously with phenotypic identification using a RENOK MicroScan panel. The MIC (Minimum Inhibitory Concentration) was determined according to the CLSI (Clinical and Laboratory Standards Institute) criteria for each antibiotic. The studied antibiotics were oxacillin, gentamicin, tetracycline, daptomycin, ampicillin, erythromycin, penicillin, nitrofurantoin, vancomycin, levofloxacin, moxifloxacin, ciprofloxacin, linezolid, ceftriaxone, Sinercid, clindamycin, rifampin, amoxicillin/clavulanate $\mathrm{k}$, trimethoprim/sulfamethoxazole, and ampicillin/sulbactam.

\subsection{Sensitivity tests with chitosan membranes}

The sensitivity test for S. aureus was performed by Kirby-Bauer's agar diffusion method [18]. From each of the identified bacterial isolates a micro-dilution was prepared in Prompt ${ }^{\mathrm{TM}}$ inoculation bottle. Afterward, plates with Muller Hinton agar were inoculated with a sterile swab and dispersed by streaking.

Chitosan based membranes were cut into $16 \mathrm{~mm}$ diameter discs and placed in triplicate on the inoculated agar with sterile forceps, ensuring direct contact between both surfaces. Each agar also included two blank controls that consisted of Whatman \# 1 paper; one was impregnated with $1 \%$ acetic acid and the other with $0.9 \%$ sodium chloride. Plates were incubated at $37^{\circ} \mathrm{C}$ for $24 \mathrm{~h}$. Lastly, the antimicrobial effect of chitosan was evident by observing the existence of inhibition zones below the membranes and inhibition halos around each membrane. 


\section{Results and discussion}

\subsection{Chitosan characterization}

The ash content of chitosan is an indication of its purity. For chitosan with $9.42 \pm 0.07 \%$ moisture, the average ash contents are $0.37 \pm 0.02 \%$. The range of ash content is $0.08 \%$ for langoustine obtained chitosan [19] and $4.0 \%$ to crab obtained chitosan [20], whereas for chitosan obtained from shrimp, the range is from 0.070 [21] to $0.832 \%$ [22]. Variations in ash content are due to the location of origin, as well as the purification and thermos-alkaline hydrolysis of chitin.

The molecular weight of chitosan determines its functional properties and its antimicrobial activity. This study found that the average molecular weight of chitosan was $119.48 \mathrm{kDa}$, estimated based on the intrinsic viscosity. With this value, chitosan can be classified as a low molecular weight (50-190 kDa) material. Therefore, the molecular weight is a reflection of the process conditions used to obtain chitosan from the purification and thermo-alkaline deacetylation of chitin. Other investigations have reported molecular weights for shrimp obtained chitosan of 136 [23], 180 [24], and $1260 \mathrm{kDa}$ [25]. While the values reported for chitosan obtained from crab shells vary from 1240 [26] to $483 \mathrm{kDa}$ [27]. For fungal chitosan, reports show low molecular weight, from 41 [24] to 110-150 kDa [25]. Davoodbasha et al. [28] conducted antimicrobial tests with commercial chitosan 100-300 kDa. Hernández-Ochoa et al. [29] also studied the antimicrobial activity of commercial chitosan with different molecular weight (low: 50-190 kDa, medium: 190-310 kDa and high: 310-375 kDa) finding satisfactory results with the lower molecular weight.

For the degree of deacetylation of chitosan, an average value of $84.59 \pm 0.87 \%(n=6)$ was found, similar to that reported in other studies; 85 [30], 82 [31], 83 [20], and 73.52\% [32] varying depending on the source of chitin and the deacetylation conditions. To determine the degree of deacetylation, a variety of methods have been employed; however, among the most repetitive are the spectrophotometric and potentiometric methods and FTIR [27]. The degree of deacetylation has a strong impact on the antimicrobial activity of chitosan, mostly because its increase raises its solubility. Therefore, a greater number of amino groups with positive charge can be obtained, which are responsible for interacting with the cell wall charge of microorganisms [33].

The FTIR technique made it possible to identify the functional groups in the chitosan molecule (Figure 1). At $881.96 \mathrm{~cm}^{-1}$, a characteristic band of the stretching of the glycosidic bond can be observed; also at 1055.62 and $1028.60 \mathrm{~cm}^{-1}$ the stretching of $\mathrm{C}-\mathrm{O}$ can be seen. It is possible to observe the bending band $\mathrm{N}-\mathrm{H}$ of the primary amide formed during deacetylation at 1545.72 $\mathrm{cm}^{-1}$ and the amine group at $1626.76 \mathrm{~cm}^{-1}$. At the position of $2884.84 \mathrm{~cm}^{-1}$ the stretching of $\mathrm{C}-\mathrm{H}$ and at $2962.02 \mathrm{~cm}^{-1}$ the tense vibration from group $\mathrm{C}-\mathrm{H}$ can be observed. Ultimately, $\mathrm{OH}$ and $\mathrm{N}-\mathrm{H}$ were identified at 3274.61 and $3359.51 \mathrm{~cm}^{-1}$, respectively. These results are similar to those reports given by references [32,34]. As reported by Shigemasa et al. [35], errors in band intensity can occurred at positions 1640 and $3450 \mathrm{~cm}^{-1}$ due to the effect of water absorption. 


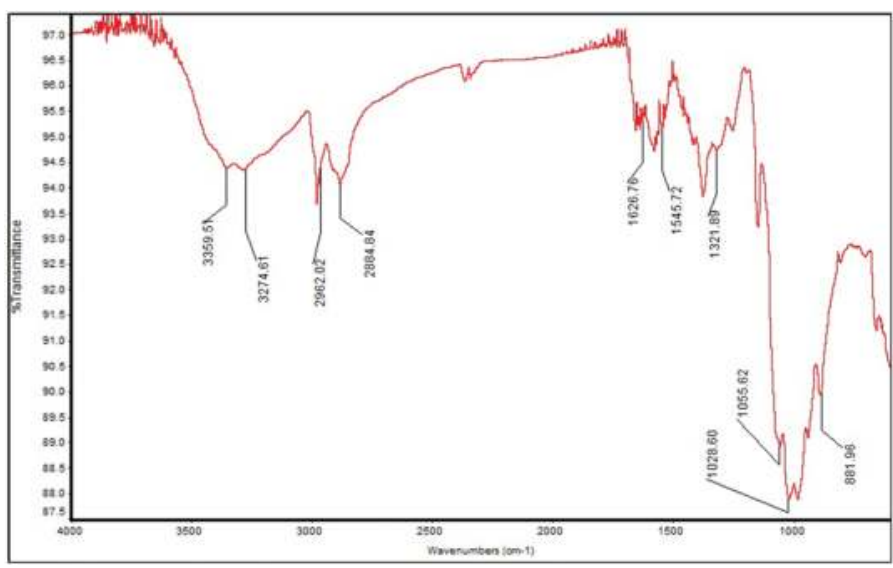

Figure 1. FTIR spectra of powdered chitosan.

\subsection{Preparation of chitosan membranes}

Dissolved chitosan is capable of forming a membrane due to the evaporation of the solvent, as well as forming intra and intermolecular hydrogen bonds between the chitosan polymer chains [36]. Chitosan membranes were prepared using pure chitosan and a mix of chitosan with glycerin or honey. All membranes were transparent, uniform, and smooth at the surface and with hard texture when chitosan concentration was increased. Pure chitosan membranes show a very pale yellow color and membranes containing honey show a brown tone. All membranes were easily removed from the polyethylene plates with $9.5 \mathrm{~cm}$ in diameter, and thickness depending on the concentration of chitosan, found in the range of $0.0131 \pm 0.0021$ and $0.0339 \pm 0.0034 \mathrm{~mm}$ for $1 \%$ and $3 \%$, respectively.

\subsection{Phenotypic identification of microorganisms}

From patients hospitalized for various reasons in a regional hospital located in northwestern Mexico, 23 infected skin ulcers derived from toes, sacral parts, coccyx, arm, and leg stumps were analyzed. The age range of the patients was from 43 to 96 years. Among the isolated and identified strains were S. aureus, Proteus mirabilis, Candida albicans, E. coli, Enterobacter aerogenes, Morganella morganii, P. aeruginosa, and Klebsiella pneumoniae. From all identified strains nine $(29.03 \%)$ were S. aureus. The incidence of S. aureus in ulcers with mild type infection is $80-90 \%$ and in moderate to severe infections, it is 66\% [37]. According to Barberán and Fariñas [38], S. aureus has been the cause of $40 \%$ of infections in skin and soft tissue [8]. Mention that the microorganisms with higher incidence in skin lesions and that increase resistance to antibiotics are E. coli, K. pneumoniae, P. mirabilis, Enterobacter cloacae, Serratia marcescens, M. morganii, Acinetobacter baumannii, and P. aeruginosa. Barberán and Fariñas [38], report that Propionibacterium acnes and S. aureus are some of the most common skin pathogens. Figure 2, left, shows the development of $S$. aureus on mannitol salt agar, medium that enables the growth of Gram- 
positive bacteria and inhibits the growth of Gram-negative. Figure 2, right, presents a microplate which includes the identification phase and the antibiogram phase with dilutions of the antibiotics.

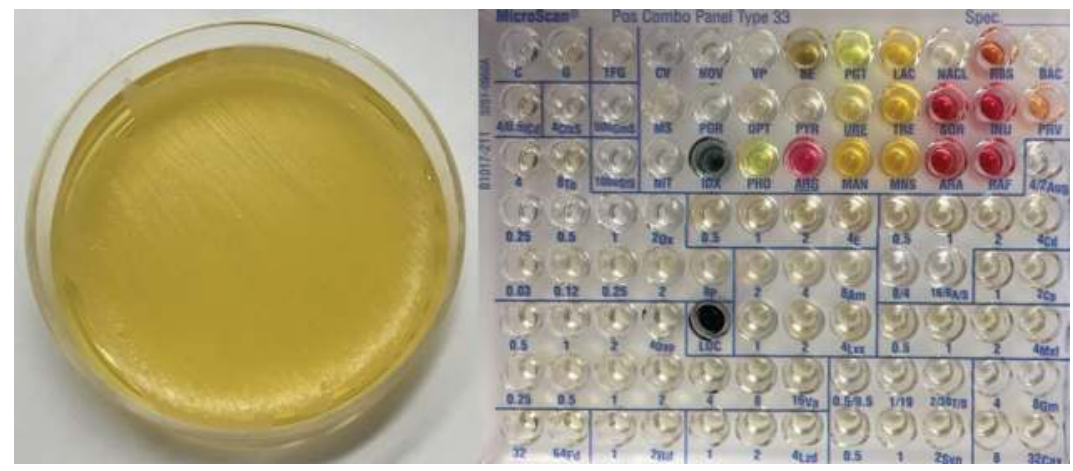

Figure 2. S. aureus growth in mannitol salt agar and microplate for identification with antibiogram.

\begin{tabular}{|c|c|c|c|c|c|c|c|c|c|}
\hline Antibiogram & UD-001 & UD-002 & UD-020 & UD-021 & UD-023 & UD-024 & UD-025 & UD-029 & UD-030 \\
\hline Oxacillin & $\mathrm{R}>2$ & $S<0.25$ & $S<0.25$ & $\mathrm{R}>2$ & $\mathrm{R}>2$ & $\mathrm{R}>2$ & $\mathrm{R}>2$ & $\mathrm{R}>2$ & $\mathrm{R}>2$ \\
\hline Gentamicin & $S<4$ & $S<4$ & $S<4$ & $\mathrm{R}>8$ & $\mathrm{R}>8$ & $S<4$ & $\mathrm{R}>8$ & $\mathrm{~S}<4$ & $S<4$ \\
\hline Tetracycline & $S<4$ & $S<4$ & $S<4$ & $\mathrm{R}>8$ & $\mathrm{R}>8$ & $\mathrm{R}>8$ & $S<4$ & $\mathrm{~S}<4$ & $S<4$ \\
\hline Daptomycin & $\mathrm{R}>4$ & $\mathrm{R}>4$ & $\mathrm{R}>4$ & $\mathrm{R}>4$ & $\mathrm{R}>4$ & $\mathrm{R}>4$ & $\mathrm{~S}<0.5$ & $\mathrm{R}>4$ & $\mathrm{~S}<0.5$ \\
\hline Ampicillin & $\mathrm{R}>8$ & $\mathrm{R}>8$ & $S<2$ & $\mathrm{R}>8$ & $\mathrm{R}>8$ & $\mathrm{R}>8$ & $\mathrm{R}>8$ & $\mathrm{R}>8$ & $\mathrm{R}>8$ \\
\hline Erythromycin & $\mathrm{R}>4$ & $\mathrm{R}>4$ & $\mathrm{R}>4$ & $\mathrm{R}>4$ & $\mathrm{R}>4$ & $\mathrm{R}>4$ & $\mathrm{R}>4$ & $\mathrm{R}>4$ & $\mathrm{R}>4$ \\
\hline Penicillin & $S<0.03$ & $\mathrm{R}>8$ & $\mathrm{R}>8$ & $\mathrm{R}>8$ & $\mathrm{R}>8$ & $\mathrm{R}>8$ & $\mathrm{R}>8$ & $\mathrm{R}>8$ & $\mathrm{R}>8$ \\
\hline Nitrofurantoin & $R>64$ & $\mathrm{~S}<32$ & $S<32$ & $\mathrm{~S}<32$ & $R>64$ & $R>64$ & $\mathrm{~S}<32$ & $\mathrm{~S}<32$ & $\mathrm{~S}<32$ \\
\hline Vancomycin & $S<0.25$ & $S<0.25$ & $\mathrm{R}>16$ & $S<0.25$ & $S<32$ & $\mathrm{R}>16$ & $\mathrm{R}>16$ & $\mathrm{R}>16$ & $\mathrm{R}>16$ \\
\hline Levofloxacin & $\mathrm{R}>4$ & $S<1$ & $\mathrm{R}>4$ & $\mathrm{R}>4$ & $\mathrm{R}>4$ & $\mathrm{R}>4$ & $\mathrm{R}>4$ & $\mathrm{R}>4$ & $\mathrm{R}>4$ \\
\hline Moxifloxacin & $\mathrm{R}>4$ & $S<0.5$ & $\mathrm{R}>4$ & $\mathrm{R}>4$ & $\mathrm{R}>4$ & $\mathrm{R}>4$ & $\mathrm{R}>4$ & $\mathrm{R}>4$ & $\mathrm{R}>4$ \\
\hline Ciprofloxacin & $\mathrm{R}>2$ & $S<1$ & $\mathrm{R}>4$ & $\mathrm{R}>2$ & $\mathrm{R}>2$ & $\mathrm{R}>2$ & $\mathrm{R}>2$ & $\mathrm{R}>2$ & $\mathrm{R}>2$ \\
\hline Linezolid & $S<1$ & $S<1$ & $\mathrm{R}>4$ & $\mathrm{R}>4$ & $\mathrm{R}>4$ & $S<1$ & $\mathrm{~S}<1$ & $\mathrm{R}>4$ & $\mathrm{R}>4$ \\
\hline Ceftriaxone & $\mathrm{R}>32$ & $S<8$ & $\mathrm{~S}<8$ & $S<8$ & $\mathrm{R}>32$ & $R>32$ & $R>32$ & $\mathrm{~S}<8$ & $R>32$ \\
\hline Synercid & $S<0.5$ & $S<0.5$ & $\mathrm{R}>2$ & $\mathrm{R}>2$ & $\mathrm{R}>2$ & $S<0.5$ & $S<0.5$ & $S<0.5$ & $S<0.5$ \\
\hline Clindamycin & $\mathrm{R}>4$ & $S<0.5$ & $S<0.5$ & $\mathrm{R}>4$ & $\mathrm{R}>4$ & $\mathrm{R}>4$ & $\mathrm{R}>4$ & $\mathrm{R}>4$ & $\mathrm{R}>4$ \\
\hline Rifampin & $S<1$ & $S<1$ & $\mathrm{~S}<1$ & $\mathrm{R}>2$ & $\mathrm{R}>2$ & $S<1$ & $\mathrm{~S}<1$ & $\mathrm{~S}<1$ & $S<1$ \\
\hline $\begin{array}{l}\text { Amoxicillin/K } \\
\text { clauvulanato }\end{array}$ & $\mathrm{R}>4 / 2$ & $\mathrm{~S}<4 / 2$ & $\mathrm{R}>4 / 2$ & $\mathrm{R}>4 / 2$ & $\mathrm{R}>4 / 2$ & $\mathrm{R}>4 / 2$ & $\mathrm{R}>4 / 2$ & $\mathrm{R}>4 / 2$ & $\mathrm{R}>4 / 2$ \\
\hline $\begin{array}{l}\text { Trimethoprim/ } \\
\text { sulfamethoxazole }\end{array}$ & $S<0.5 / 9.5$ & $S<0.5 / 9.5$ & $R>2 / 38$ & $R>2 / 38$ & $R>2 / 38$ & $S<0.5 / 9.5$ & $R>2 / 38$ & $R>2 / 38$ & $S<0.5 / 9.5$ \\
\hline $\begin{array}{l}\text { Ampicillin/ } \\
\text { sulbactam }\end{array}$ & $R>16 / 8$ & $R>16 / 8$ & $\mathrm{~S}<8 / 4$ & $R>16 / 8$ & $R>16 / 8$ & $\mathrm{~S}<8 / 4$ & $\mathrm{~S}<8 / 4$ & $\mathrm{~S}<8 / 4$ & $\mathrm{~S}<8 / 4$ \\
\hline
\end{tabular}

$\mathrm{R}$, resistant; $\mathrm{S}$, sensitive.

Table 1. Antibiogram of chronic ulcers from S. aureus isolates. 


\subsection{S. aureus sensitivity to antibiotics}

Table 1 shows the minimum inhibitory "in vitro" amount of twenty antibiotics against nine strains of $S$. aureus studied with a RENOK MicroScan panel. Specifically, seven of the nine S. aureus strains are sensitive to rifampin (MIC $<1 \mu / \mathrm{ml})$, while the least effective antibiotics were ampicillin (MIC $>8 \mu / \mathrm{ml}$ ), erythromycin (MIC $>4 \mu / \mathrm{ml}$ ), penicillin (MIC $>8 \mu / \mathrm{ml}$ ), levofloxacin (MIC $>4 \mu / \mathrm{ml}$ ), moxifloxacin (MIC $>4 \mu / \mathrm{ml}$ ), ciprofloxacin (MIC $>2 \mu / \mathrm{ml}$ ), and clavulanate amoxycillin (MIC $>4 / 2 \mu / \mathrm{ml}$ ). In addition, eight of the nine strains were detected to be multiresistant to more than ten antibiotics. Additionally, one isolated showed sensitivity to vancomycin, while another was sensitive to 15 of the 20 studied antibiotics.

Figure 3 shows that most strains are resistant to the most commonly used antibiotics. All isolates were resistant to erythromycin. Only one of the nine strains showed sensitivity toward ampicillin, penicillin, levofloxacin, ciprofloxacin, and amoxicillin.

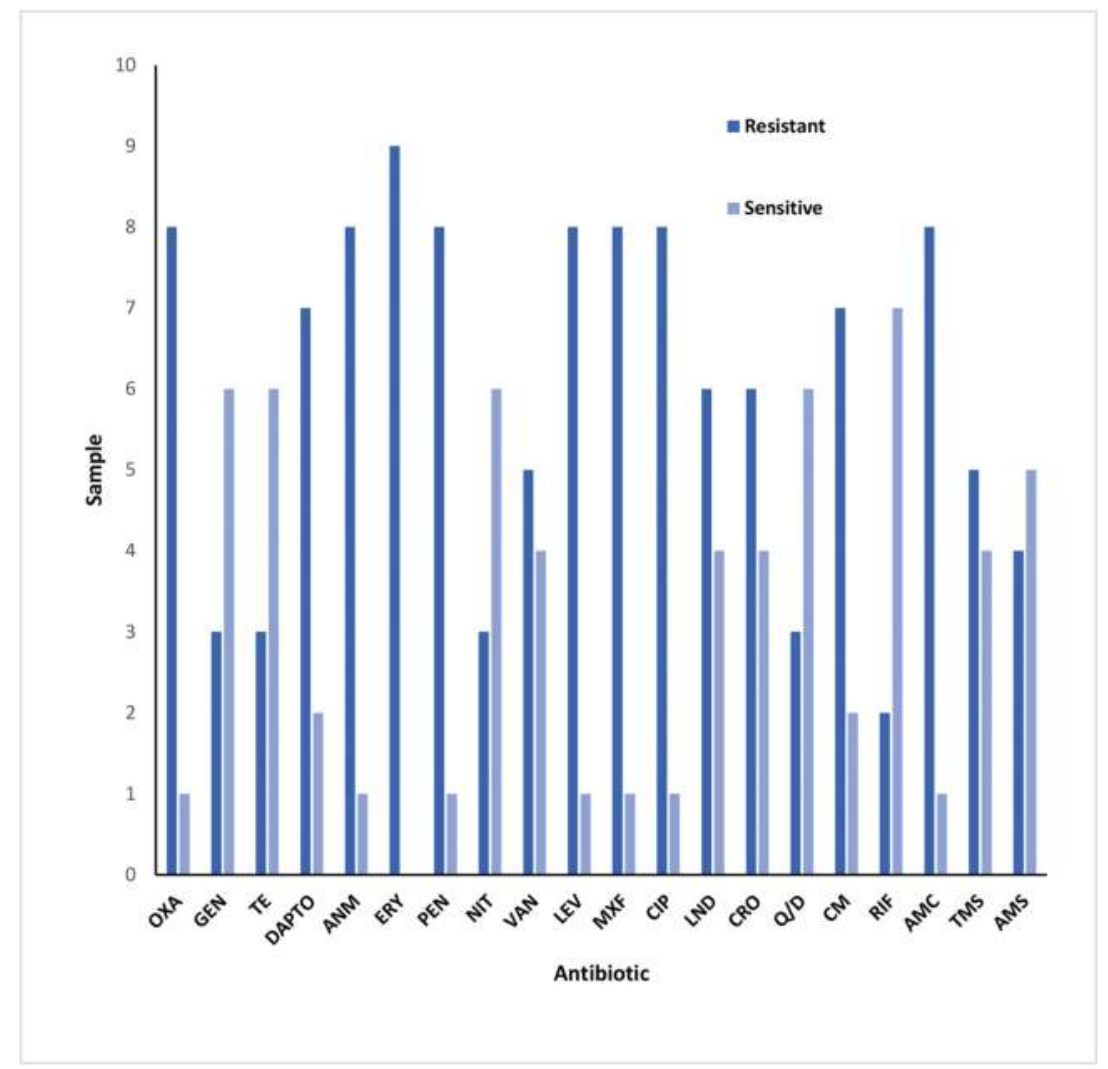

Figure 3. Antibiotic sensitivity and resistant toward S. aureus. 
The most commonly used antibiotics for $S$. aureus treatments are vancomycin, linezolid, daptomycin, tigecycline, rifampin, clindamycin, cloxacillin, clindamycin, cotrimoxazol, and doxycycline [1]. Daptomycin has superior bactericidal action than other drugs against $S$. aureus [38]. Chirinos-Saldaña et al. [39] found that S. aureus isolated from conjunctivitis shows high sensitivity toward vancomycin, ciprofloxacin, and gentamicin. Antibiotic resistance is generated due to prolonged and inappropriate use of antibiotics [39]. Furthermore, if the bacterial population density in the infection is high, $S$. aureus can become resistant to most antibiotics used in monotherapy [40].

\subsection{S. aureus sensitive chitosan membranes}

The "in vitro" antimicrobial activity assays with chitosan membranes for S. aureus were carried out by the agar diffusion method. Figure 4 presents the absence of microbial growth below the membranes. It was also observed that no inhibition halo or clear zones were formed around the membrane explained because chitosan is unable to diffuse through agar. However, chitosan membranes added with honey presented a small zone of inhibition, confirming that chitosan only has antimicrobial effect by direct contact and cannot migrate into the agar. Likewise, microbial growth occurred in both blank controls with acetic acid and sodium chloride, which means that the antimicrobial effect cannot be attributed to these chemicals.
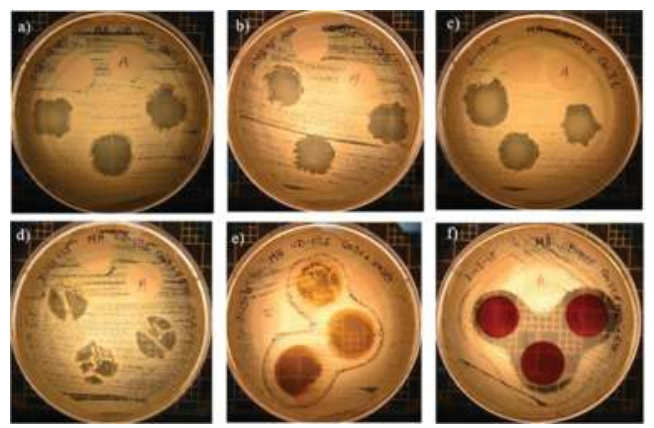

Figure 4. S. aureus susceptibility to chitosan membranes by agar diffusion method. Chitosan $1 \%$ (a), chitosan $2 \%$ (b), chitosan $3 \%$ (c), chitosan $2 \%+$ gly (d), chitosan $2 \%+$ honey (e), and chitosan $2 \%+$ honey + gly (f).

In a study by Hernández-Ochoa et al. [29], with S. typhimurium, S. aureus, and Listeria monocytogenes, results reported that chitosan membranes with essential oils (Cuminum cyminum and Eugenia caryphyllata) can present inhibition halos, while for pure chitosan membranes, the effect is shown only by direct contact.

The antimicrobial properties of chitosan mainly depend on the degree of deacetylation and molecular weight, as well as $\mathrm{pH}$ and ionic strength of the medium [41]. El-tahlawy et al. [42] and Hosseinnejad and Jafari [43] reported that low molecular weight chitosan can penetrate into the cell and inhibits mRNA and protein synthesis. Chitosan oligomers have higher antimicrobial effect due to their shorter chain and free amino groups from D-glucosamine [44]. 
Similarly, Champer et al. [45] reported that the amount of free amino groups influence the antibacterial properties of chitosan. Likewise, Wang et al. [46] state that all bacteria possess negative charges; therefore, they are easily captured by the protonated amine groups of chitosan and lose their reproductive functions and bioactivity. Acetic acid has an effect on the solubility of the polymer and on the protonation of the amino groups.

Kim et al. [47] evaluated the antimicrobial activity of chitosan membranes of different molecular weights with L. monocytogenes, E. coli, and Salmonella typhimutium and found that chitosan with low molecular weight has better effect. No et al. [48] reported that chitosan $(1671,746$, 224 , and $28 \mathrm{kDa}$ ) and chitosan oligomers $(22,10,7,3,2$, and $1 \mathrm{kDa})$ can inhibit the growth of L. monocytogenes, Bacillus megaterium, Bacillus cereus, S. aureus, and Lactobacillus bulgaricus.

Additionally, it was observed that the membranes tend to increase their diameter by staying in contact with the agar, thus increasing the antimicrobial effect by contact. Table 2 presents the increase in diameter and area of the membranes at the end of agar diffusion assay. For pure chitosan membranes, it was found that an increase in size is directly proportional to its concentration. It was also observed that the addition of glycerin or honey increases the size of the chitosan membranes by $2 \%$. The $2 \%$ chitosan membranes mixed with honey and glycerin showed the greatest increase, however, bacterial growth was observed.

\begin{tabular}{|c|c|c|}
\hline Membranes & Increased radius $(\mathrm{mm})^{\mathrm{a}}$ & Increase in contact area $(\%)^{\mathrm{b}}$ \\
\hline Qo $1 \%$ & $9.01 \pm 4.97$ & $20.03 \pm 14.90$ \\
\hline Qo $2 \%$ & $9.39 \pm 6.48$ & $30.61 \pm 17.33$ \\
\hline Qo 3\% & $9.70 \pm 9.58$ & $39.80 \pm 25.80$ \\
\hline Qo $2 \%$ + gly & $9.74 \pm 6.34$ & $40.34 \pm 17.38$ \\
\hline Qo $2 \%+$ miel & $11.20 \pm 4.65$ & $65.38 \pm 20.29$ \\
\hline Qo $2 \%$ + miel + gly & $11.20 \pm 4.53$ & $88.32 \pm 21.73$ \\
\hline
\end{tabular}

Table 2. Comparison of the increase in radii and areas of chitosan membranes.

Vlacha et al. [49] reported that free hydroxyl groups from chitosan interact with the moist atmosphere increasing the diameter of the membrane. Also, Zamora-Mora et al. [50] mentioned that pure chitosan membranes show a higher water holding capacity due to the hydrophilicity of the chitosan. According to Estrada et al. [51], honey potentiates the antimicrobial activity of chitosan due to chemical action of its components; hydrogen peroxide, organic acids and flavonoids, nectar, pollen, and propolis. For Grade et al. [52], plasticizers provide flexibility to the membranes, but weaken the intermolecular forces and cause the penetration of water through the membrane increasing its size [23]. 


\section{Conclusion}

Different types of chitosan-based membranes mixed with glycerol and honey were developed and characterized. These membranes showed antimicrobial activity against $S$. aureus of clinical origin. Additionally, strains of $S$. aureus isolated from infected ulcers were found to have multidrug resistance to antibiotics. For future research where these materials will be applied in the treatment of chronic ulcers, it is important to recognize that the antimicrobial effect is given by direct contact in order to ensure that ulcers are completely covered with the membranes. These materials are an alternative for controlling intrahospital microorganisms without toxic hazards from antibiotics.

\section{Acknowledgements}

AA Escárcega-Galaz gratefully acknowledges the Consejo Nacional de Ciencia y Tecnología (CONACYT) by PhD scholarship: 417707. This research was funded by the Instituto Tecnológico de Sonora (Project PROFAPI-00471) and by the Consejo Nacional de Ciencia y Tecnología (PDCPN2014: 248160).

\section{Author details}

Ana A. Escárcega-Galaz ${ }^{1}$, Jaime López-Cervantes ${ }^{1}$, Dalia I. Sánchez-Machado ${ }^{1 *}$, Olga R. Brito-Zurita ${ }^{2}$ and Olga N. Campas-Baypoli ${ }^{1}$

*Address all correspondence to: dalia.sanchez@itson.edu.mx

1 Department of Biotechnology and Food Sciences, Technological Institute of Sonora, Cd. Obregon, Sonora, Mexico

2 Medical Research Unit in Clinical Epidemiology, High Speciality Medical Unit, NorthWestern National Medical Center, Mexican Social Security Institute, Ciudad Obregón, Sonora, México

\section{References}

[1] Mensa J, Barberán J, Llinares P, Picazo JJ, Bouza E, Älvarez F, Borges M, Serrano R, León C, Guirao X, Arias J, Carreras E, Sanz MA, García JA. Guidelines for the treatment on infections caused by methicillin-resistant Staphylococcus aureus. Rev Esp Quimioter. 2008;21(4):234-258. ISSN-e: 0214-3429. 
[2] Velazco E, Nieves B, Araque M, Calderas Z. Epidemiology of Staphylococcus aureus nosocomial infections in a high-risk neonatal unit. Enf Infecc Microbiol Clin. 2002;20(7): 321-325 doi:10.1016/S0213-005X(02)72808-5.

[3] Anisha BS, Sankar D, Mohandas A, Chennazhi KP, Nair SV, Jayakumar R. Chitosanhyaluronan/nano chondroitin sulfate ternary composite sponges for medical use. Carbohyd Polym. 2013;92:1470-1476. doi:10.1016/j.carbpol.2012.10.058

[4] Dantas MDM, Cavalcante DRR, Araújo FEN, Barreto SR, Aciole GTS, Pinheiro ALB, Ribeiro MAG, Lima-Verde IB, Melo CM, Cardoso JC, Albuquereque RLC. Improvement of dermal burn healing by combining sodium alginate/chitosan-based films and low level laser therapy. J Photochem Photobiol B. 2011;105:51-59. doi:10.1016/j.jphotobiol.2011.06.009

[5] Mi F-L, Shyu S-S, Wu Y-B, Lee S-T, Shyong J-Y, Huang R-N. Fabrication and characterization of a sponge-like asymmetric chitosan membrane as a wound dressing. Biomaterials. 2001;22:165-173. doi:10.1016/S0142-9612(00)00167-8

[6] Sánchez-Saldaña L, Sáenz-Anduaga E. Bacterial cutaneous infections. Dermatol Peru. 2006;16(1):7-31.

[7] Abbaspour M, Makhmalzadeh BS, Rezaee B, Shoja S, Ahangari Z. Evaluation of the antimicrobial effect of chitosan/polyvinyl alcohol electrospun nanofibers containing mafenide acetate. Jundishapur J Microbiol. 2015;8(10):e24239. doi: 10.5812/jjm.24239

[8] Corrales L, Castillo A, Melo A. In vitro evaluation of antibacterial potential of Croton lechleri against bacterial isolates from patients with skin ulcers. NOVA. 2013;11(19):5163. ISSN: 1794-2470.

[9] Flores-Reyes M, Camarillo-Romero MS, Flores-Estrada J, Flores-Merino MV. Polymeric skin substitutes for the treatment of diabetic foot ulcer. Medicina e Investigación. 2015;3(1):74-78. http://dx.doi.org/10.1016/j.mei.2015.02.006.

[10] Tavaria FK, Soares JC, Reis IL, Paulo MH, Malcata FX, Pintado ME. Chitosan: antimicrobial action upon staphylococi after impregnation onto corron fabric. J App Microbiol. 2012;112:1034-1041. ISSN: 1364-5072

[11] Didenko LV, Gerasimenko DV, Konstantinova ND, Silkina TA, Avdienko ID, Bannikova GE, Varlamov VP. Ultrastructural study of chitosan effect on Klebsiella and Staphylpcocci. Bull Exp Biol Med. 2005;140(3):356-360. DOI: 10.1007/s10517-005-0489-6

[12] Woo CH, Choi YC, Choi JS, Lee HY, Cho YW. A bilayer composite composed of TiO2incorporated electrospun chitosan membrane and human extracellular matrix sheet as a wound dressing. J Biomater Sci Polym Ed. 2015;26(13):841-854. http://dx.doi.org/ 10.1080/09205063.2015.1061349.

[13] Sánchez-Duarte RG, Sánchez-Machado DI, López-Cervantes J, Correa-Murrieta M.A. Adsorption of allura red dye by cross-linked chitosan from shrimp waste. Wat Sci Technol. 2012;48:618-623. doi: 10.2166/wst.2012.900 
[14] AOAC. Official methods of analysis.18th ed. In: Williams S, editor. Arlington, VA: Association of Official Analytical Chemists. 2005.

[15] Liu D, Wei Y, Yaob P, Jiang L. Determination of the degree of acetylation of chitosan by UV spectrophotometry using dual standards. Carbohyd Res. 2006;341:782-785. doi: 10.1016/j.carbpol.2005.11.007

[16] Solis Y, Peniche C, García N, Davidenko N. Un procedimeinto biomimético novedoso para obtener composites de quitosanahidroxipatita. VII Congreso de la Sociedad Cubana de Bioingenieria. 2007.

[17] Beil S, Schamberger A, Naumann W, Machill S, Van Pée K.H. Determination of the degree of N-acetylation (DA) of chitin and chitosan in the presence of water by first derivative ATR FTIR spectroscopy. Carbohyd Polym. 2012;87:117-122. doi:10.1016/ j.carbpol.2011.07.025

[18] Pérez A, Rojas J, Rodriguez J, Arrieta I, Arrieta Y, Rodríguez A. Antibacterial activity of chitosan acid solutions obtained from shrimp exoskeleton. Rev Colomb Biotecnol. 2014;16(1):104-110. http://dx.doi.org/10.15446/rev.colomb.biote.v16n1.44251

[19] Mármol Z, Gutierrez E, FerrerJ, Rincin M. Desacetilación termoalcalina de quitina de conchas de camarón. Multiciencias. 2004;4(2):91-95. ISSN: 1317-2255

[20] Colina M, Ayala A, Roncón D, Molina J, Medina J, Ynciarte R, Vargas J, Montilla B. Enaluación de los procesos para la obtención química de quitina y quitosano a partir de desechos de cangrejos. Escala piloto e industrial. Rev Iberoam Polím. 2014;15(1):2143. ISSN-e:01216651

[21] Gildberg A, Stenberg E. A new process for advanced utilisation of shrimp waste. Process Biochem. 2001;36. 809-812. 10.1016/s0032-9592(00)00278-8

[22] Sini T, Santhosh S, Mathew P. Study on the production of chitin and chitosan from shrimp shell by using Bacillus subtilis fermentation. Carbohyd Res. 2007;342:24232429. doi:10.1016/j.carres.2007.06.028

[23] Rodríguez-Núñez JR, Madera-Santa TJ, Sánchez-Machado DI, López-Cervantes J. Chitosan/hydrophilic plasticizer-based films: preparation, physicochemical and antimicrobial properties. J Polym Environ. 2014;22:41-51. DOI 10.1007/ s10924-013-0621-z

[24] Fernández-Pan I, Maté JI, Gardrat C, Coma V. Effect of chitosan molecular weight on the antimicrobial activity and release rate of carvacrol-enriched films. Food Hydrocolloid. 2015; 51:60-68. http://dx.doi.org/10.1016/j.foodhyd.2015.04.033

[25] Bierhalz AC, Westin CB, Moraes AM. Comparison of the properties of membranes produced with alginate and chitosan from mushroom and from shrimp. Int J Biol Macromol. 2016; 91:496-504. http://dx.doi.org/10.1016/j.ijbiomac.2016.05.095 
[26] Qun C, Li H, Xiao Q, Lu Y, Zhu J, Du Y. Water-solubility of chitosan and its antimicrobial activity. Carbohyd Polym. 2006;63:367-374. doi:10.1016/j.carbpol. 2005.09.023

[27] Yen MT, Yang JH, Mau JL. Physicochemical characterization of chitin and chitosan from crab shells. Carbohyd Polym. 2009;75:15-21. doi:10.1016/j.carbpol. 2008.06.006

[28] Davoodbasha M, Kim AC, Lee SY, Kim JW. The facile synthesis of chitosan-based silver nano-biocomposites via a solution plasma process and their potential antimicrobial efficacy. Arch of Biochem Biophys. 2016;605:49-58. http://dx.doi.org/10.1016/j.abb. 2016.01.013

[29] Hernández-Ochoa L, Gonzales-Gonzales A, Gutiérrez-Mendez N, Muñoz-Castellanos LN, Quintero-Ramos A. Study of the antibacterial activity of chitosan-based films prepared with different molecular weights including spices essential oils and functional extracts as antimicrobial agents. Rev Mex Ing Quím. 2011;10(3):455-463. ISSN: $1665-2738$

[30] Baskar D, Sampath Kumar TS. Effect of deacetylation time on the preparation, properties and swelling behavior of chitosan films. Carbohyd Polym. 2009; 78:767-772. doi: 10.1016/j.carbpol.2009.06.013

[31] Alvarenga ES, Olivera CP, Bellato CR. An approach to understanding the deacetylation degree of chitosan. Carbohyd Polym. 2010;80:1155-1160. doi:10.1016/j.carbpol. 2010.01.037

[32] Correa LS, Zuluaga F, Valencia C, Godoy JE. Elaboración de andamios porosos osteoinductivos de poli(ácido L-láctico)/quitosano para la regeneración de tejido ósea. Revista Colombiana de Materiales. 2015;6:34-53. ISSN: 2256-1013

[33] Ayala G. Antimicrobial effect of chitosan: a review. Revista Scientia Agroalimentaria. 2015;2:32-38. ISSN: 2339-4684

[34] Barros I, Guzmán L, Tarón A. Extraction and quantitative comparison of chitin obtained from the shell of Callinectes sapidus and Penaeus vannamei. Rev UDCA Act Div. 2015;18(2):227-234. ISSN:0123-4226

[35] Shigemasa Y, Matsuura H, Sashiwa H, Saimoto H. Evaluation of different absorbance ratios from infrared spectroscopy for analyzing the degree of deacetylation in chitin. Int J Biol Macromol. 1996;18:237-242. doi:10.1016/0141-8130(95)01079-3

[36] Cárcamo CA. Preparación de films de complejo polieletrolito quitosano-alginato y comparación de sus propiedades mecánicas y biológicas con films de quitosano [Tesis]. Santiago, Chile: 2005.

[37] Sarratea MPF. Manejo diagnóstico y terapéutico de las úlceras cutáneas crónicas infectadas. Jano: Medicina y humanidades. 2011;1767:61-65. 
[38] Barberán J, Fariñas MC. Daptomycin in complicated skin and soft tissue infections. Enferm Infecc Microbiol Clínica. 2012; 30(1):33-37. doi:10.1016/ S0213-005X(12)70069-1

[39] Chirinos-Saldaña $P$, Graue-Hernández EO, Hernández-Camarena JC, Navas A,Ramírez-Miranda A, Romero-Díaz L, Vizuet-García L, Ortiz-Casas M, LópezEspinosa NL, Gaona-Juárez C, Bautista-Hernández LA, Bautista-de Lucio VM. Microbiological profile and antibacterial sensitivity of conjunctival infections isolated microorganisms from the Fundación Conde de Valenciana Ophthalmological Institute. Report of the year 2012. Rev Mex Oftalmo. 2014;88(2):73-77. http:// dx.doi.org/10.1016/j.mexoft.2014.01.001

[40] Espinosa LE, Vega ME, Rodríguez AA, Jiménez LV, Morales E. Caracterización de Staphylococcus aureus resistente a meticilina aislado de pacientes con piodermitis. Dermatol Rev Mex. 2013;57:165-170.

[41] Chung YC, Wang HL, Chen YM, Li SL. Effect of abiotic factors on the antibacterial activity of chitosan against waterborne pathogens. Bioresour Technol. 2003;88:179-184. doi:10.1016/S0960-8524(03)00002-6

[42] El-tahlawy KF, El-Bendary MA, Elhendawy AG, Hudson SM. The antimicrobial activity of cotton fabrics treated with different crosslinking agents and chitosan. Carbohyd Polym. 2005;60:421-430. doi:10.1016/j.carbpol.2005.02.019

[43] Hosseinnejad M, Jafari SM. Evaluation of different factors affecting antimicrobial properties of chitosan. Int J Biol Macromol. 2016;85:467-475. http://dx.doi.org/10.1016/ j.ijbiomac.2016.01.022

[44] Xia W, Liu P, Zhang J, Chen J. Biological activities of chitosan and chitooligosacharides. Food Hydrocolloid. 2011;25:170-179. doi:10.1016/j.foodhyd.2010.03.003

[45] Champer J, Patel J, Fernando N, Salehi E, Wong V, Kim J. Chitosan against cutaneous pathogens. AMB Express. 2013;3(37):1-8. doi:10.1186/2191-0855-3-37

[46] Wang T, Zhu XK, Xue XT, Wu DY. Hydrogel sheets of chitosan, honey and gelatin as burn wound dressings. Carbohyd Polym. 2012;88:75-83. doi:10.1016/j.carbpol. 2011.11.069

[47] Kim KW, Min BJ, Kim YT, Kimmel RM, Cooksey K, Park SI. Antimicrobial activity against foodborne pathogens of chitosan biopolymer films of different molecular weights. Food Sci Technol. 2011;44:565-569. doi:10.1016/j.lwt.2010.08.001

[48] No HK, Park NY, Lee SH, Meyers SP. Antibacterial activity of chitosans and chitosan oligomers with different molecular weights. Int J Food Microbiol. 2002;74:65-72. doi: 10.1016/S0168-1605(01)00717-6

[49] Vlacha M, Giannakas A, Katapodis P, Stamatis H, Ladavos A, Barkoula NM. On the efficiency of oleic acid as plasticizer of chitosan/clay nanocomposites and its role on 
thermo-mechanical, barrier and antimicrobial properties - comparison with glicerol. Food Hydrocolloid. 016;57:10-19. http://dx.doi.org/10.1016/j.foodhyd.2016.01.003

[50] Zamora-Mora V, Sibaja M, Vega-Baudrit J. Diseño de un biofilm a partir de colágeno de pieles de tilapia y de quitosano de camarón como soporte para aplicaciónes en ingeniería de tejidos. Revista iberoamericana de polímeros. 2010;11(7):607-619.

[51] Estrada H, Gamboa MM, Chaves C, Arias ML. Evaluation of the antimicrobial action of honey against Staphylococcus aureus, Staphylococcus epidermidis, Pseudomonas aeruginosa, Escherichia coli, Salmonella enteritidis, Listeria monocytogenes and Aspergillus niger. Evaluation of its microbiological charge. Arch Latinoam Nutr. 2005;55(2):161-171. ISSN: 0004-0622

[52] Grade R, Pessan LA, Carvalho A. Ternary melt blends of poly(lactic acid)/poly(vinylalcohol)-chitosan. Ind Crrop Prod. 2015;72:159-165. http://dx.doi.org/10.1016/ j.indcrop.2014.12.041 